\title{
Functionalization of Macrobicyclic Amino Cryptands With Photoactive Fluorophoric Units for Metal Ion Sensing Application
}

\author{
Lakshminarayanan Piramuthu, Kumaresan Murugesan, Vanthana Jeyasingh, Sudha \\ Lakshminarayanan, Selvapalam Narayanan
}

Abstract: In this report we discussed the photo physical properties of two hexaanthryl substituted cryptands, $L^{1}$ and $L^{2}$ respectively. Further, photophysical studies of $L^{1}$ and $L^{2}$ with different transition metal ions as an input are carried out to probe these molecules as metal ion sensors in solution.

Keywords : Cryptands, Metal Sensors, Anthracene, Photo Electron Transfer.

\section{INTRODUCTION}

In our earlier report, we reported the single-crystal X-ray structural feature of the chloroform-benzene-chloroform adduct which stabilized through different weak interactions inside the channel of a supramolecular assembly formed by van der Waals stacking of a highly symmetric hexaanthryl-substituted octaaminocryptand, $\mathrm{L}^{1}$. In the Functionalized cryptands ${ }^{2}$ compounds $\mathrm{L}^{1}$ and $\mathrm{L}^{2}$ anthryl moieties are attached to nitrogen centers of cryptand architecture via methylene spacer, these molecules could be of interest for both anion and cation sensing applications. Detailed photophysical studies of $\mathrm{L}^{1}$ and $\mathrm{L}^{2}$ with different metal ions as solution state input was carried out to probe these molecules as chemical sensors of metals ions in solution state.

\section{EXPERIMENTAL}

The cryptands $\mathrm{L}^{1}$ and $\mathrm{L}^{2}$ are synthesized as per our reported

Revised Manuscript Received on December 16, 2019.

* Correspondence Author

"Lakshminarayanan Piramuthu, Department of Chemistry, Kalasalingam Academy of Research and Education (Deemed to be University), Krishnankoil-626126, Tamilnadu, India. Email: lakshmi16narayanan@gmail.com

Kumaresan Murugesan, Department of Chemistry, Kalasalingam Academy of Research and Education (Deemed to be University), Krishnankoil-626126, Tamilnadu, India. Email kavikums39@gmail.com

Vanthana Jeyasingh, Department of Chemistry, Kalasalingam Academy of Research and Education (Deemed to be University), Krishnankoil-626126, Tamilnadu, India. Email: vanthana14294@gmail.com

Sudha Lakshminarayanan, Department of Chemistry, Kalasalingam Academy of Research and Education (Deemed to be University), Krishnankoil-626126, Tamilnadu, India. Email: sudha28lakshmi@gmail.com

Selvapalam Narayanan, Department of Chemistry, Kalasalingam Academy of Research and Education (Deemed to be University), Krishnankoil-626126, Tamilnadu, India. Email: s22elva@gmail.com literature procedure and isolated as the free bases[2]-[6].

\section{RESULTS AND DISCUSSION}

A. Photophysical studies on $L^{1}$ and $L^{2}$

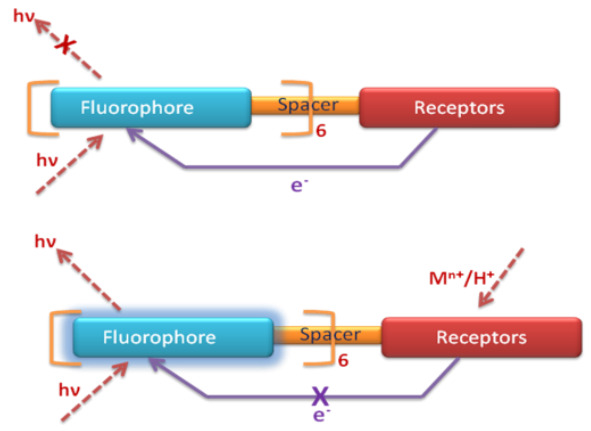

Scheme 1. Schematic representation of Photo Electron Transfer (PET) system

The anthryl derivatized cryptands, $\mathrm{L}^{1}$ and $\mathrm{L}^{2}$ show the format of "fluorophore-spacer-receptor" configuration (Scheme 1), where fluorophore is anthryl group, spacer is methylene and receptor is the cryptand unit. The fluoroionophores show less fluorescence output due to nitrogen lone pairs active in excited state with efficient photo induced intramolecular electron transfer (PET). The mechanism of PET in case of "fluorophore-spacer-receptor" configuration is well established in the literature[7] However, the fluorescence can be recovers to various aspects in the sight of various metal ions and protons as well. Cryptand unit and transition metal ion while complexation or protonation in a dry (THF) system, PET systems exhibits the nitrogen lone pairs are responsible for PET are engaged in bonding as shown in Scheme 1.

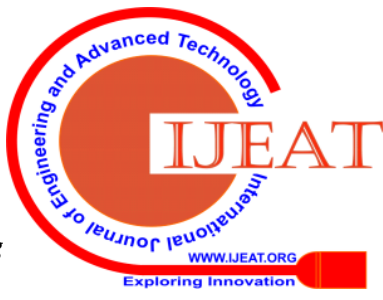




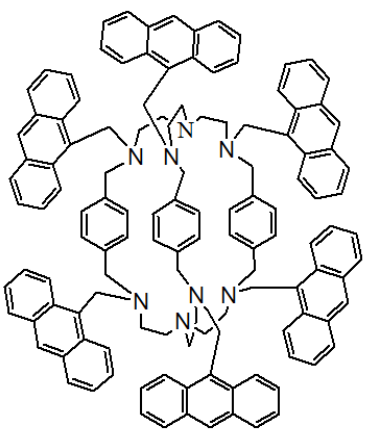

$\mathbf{L}^{1}$

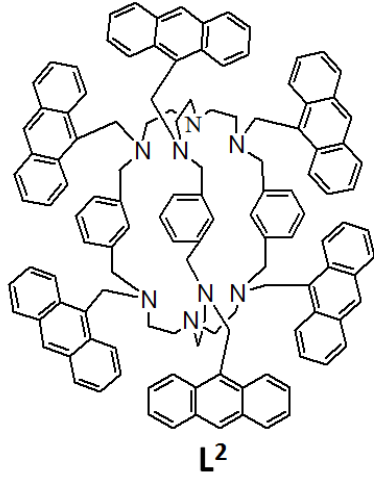

$\mathrm{L}^{2}$
Scheme 2. Structures of functionalized cryptands $\mathrm{L}^{1}$ and $\mathrm{L}^{2}$ used in these metal sensing studies

B. UV-Visible absorption spectroscopy of free $L^{1}$ and $L^{2}$ and in the presence of metal ion inputs

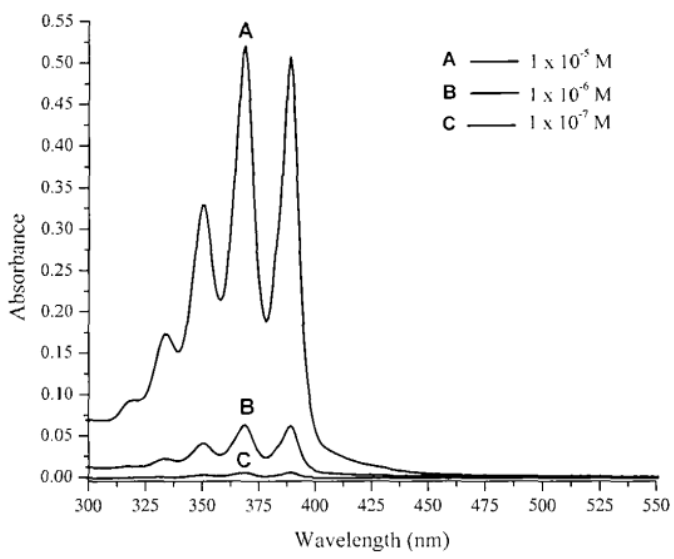

Fig. 1. UV-vis absorption spectra of free $\mathrm{L}^{1}$ recorded at different concentrations in dry THF.

UV -Visible spectra of $\mathrm{L}^{1}$ and $\mathrm{L}^{2}$ were recorded in various concentrations such as $0.00001,0.000001$ and $0.0000001 \mathrm{M}$ in dry THF (Fig. 1). In case of $\mathrm{L}^{1}$ optical density OD at $\lambda_{\max }$, $(368 \mathrm{~nm})$ for the above three concentrations are 0.5124 , 0.0559 , and 0.0058 respectively whereas in $\mathrm{L}^{2}$ corresponding OD are $0.5209,0.0516$. and 0.005 respectively (Fig. 1). The UV-Vis absorption band of the $\mathrm{L}^{1}$ and $\mathrm{L}^{2}$ were characteristic of 9-monoalkyl functionalized anthracence with well-resolved structures with the $(0,0)$ band observed at 388.9 $\mathrm{nm}$ and vibrational structures at $(368.8,350.3$ and $333.7 \mathrm{~nm})$ for $\mathrm{L}^{1}$ and the $(0,0)$ band observed at $389.1 \mathrm{~nm}$ and vibrational structures at $368.7 \mathrm{~nm}, 350.4 \mathrm{~nm}$ and $333.1 \mathrm{~nm}$ for $\mathrm{L}^{2}$. These indicates where nitrogen lone pairs of the receptor part and the anthracence units has no interaction in the ground state. From these experiments $1 \times 10^{-6} \mathrm{M}$ concentration $(0.0<$ $0.1)$ is chosen for emission experiments to avoid the self-quenching from the concentrated fluoroionophores. In $\mathrm{L}^{1}$ and $\mathrm{L}^{2}$ a bathochromic shifts of the UV-peak positions $5 \mathrm{~nm}$ and $3 \mathrm{~nm}$ respectively were observed in addition of $\mathrm{Cr}(111)$ whereas all other competitive metal ions and including $\mathrm{H}^{+}$do not show any shift or shifts less than $3 \mathrm{~nm}$ in dry THF. Detailed UV-Vis absorption data are listed in the Table I.

Table-I : UV-vis spectral data of $\mathrm{L}^{1}$ and $\mathrm{L}^{2}$ with various metal ion input at $298 \mathrm{~K}$

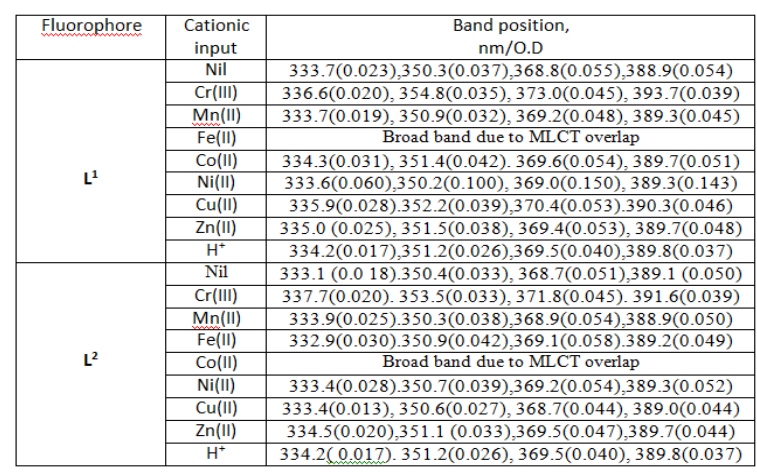

\section{Emission spectra of free $L^{1}$ and $L^{2}$ and in the sight of different metal ions inputs}

$1 \mathrm{X} 10^{-6} \mathrm{M}$ THF solution of compounds, $\mathrm{L}^{1}$ and $\mathrm{L}^{2}$ containing a Receptor-Spacer-Fluorophore configuration show a low intense well-resolved anthracene monomer emission at $390,410.3,439.4 \mathrm{~nm}$ and $390.2,411.8 .436 .7 \mathrm{~nm}$ respectively (Fig. 3 and Table III). The details of emission data of both these fluoroionophores in presence of various metal inputs are also listed in Table II. The quantum yield $\Phi_{\mathrm{F}}$ is calculated 0.012 and 0.013 or $\mathrm{L}^{1}$ and $\mathrm{L}^{2}$ respectively in THF at $5^{\circ} \mathrm{C}$ (Table II), versus $\Phi_{\mathrm{F}}$ of 0.297 for anthracene in ethanol medium with same exploratory conditions, i.e., a reduced by a factor of about 25 , which was thought to be because of the PET from the lone pairs of nitrogen to the excited state of anthracene moiety.

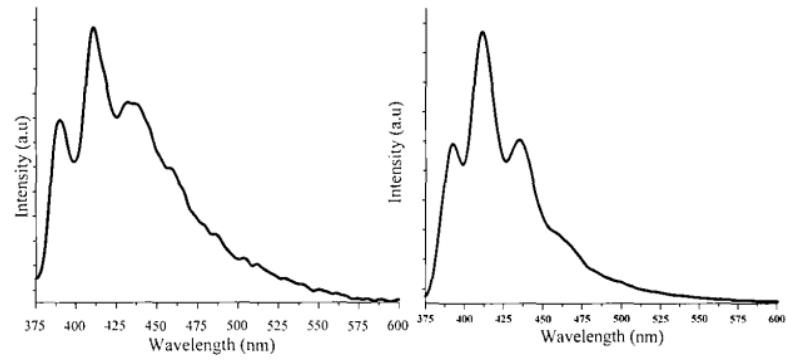

(a)

(b)

Fig. 3. Fluorescence emissions spectra of (a) $\mathrm{L}^{1}$ and (b) $\mathrm{L}^{2}$ in dry THF at $1 \times 10^{-6}$.

Table- II: Fluorescence spectral data of $\mathrm{L}^{1}$ and $\mathrm{L}^{2}$ with different metal ion input at $298 \mathrm{~K}$.

\begin{tabular}{|c|c|c|}
\hline Fluorophore & $\begin{array}{c}\text { Cationic } \\
\text { input }\end{array}$ & Band position, nm/intensity a.u \\
\hline \multirow{5}{*}{} & Nil & $390.0(73.6), 410.3(113.2) .439 .4(78.3)$ \\
\cline { 2 - 3 } & $\mathrm{Cr}(\mathrm{III})$ & $398.2(715.3) .421 .7(817.9) .442 .0(482.3)$ \\
\cline { 2 - 3 } & $\mathrm{Mn}(\mathrm{II})$ & $390.8(244.4) .413 .4(302.4), 439.7(232.5)$ \\
\cline { 2 - 3 } & $\mathrm{Fe}(\mathrm{II})$ & $397.4(484.7), 420.4(582.5), 44 \mathrm{H}(341.3)$ \\
\cline { 2 - 3 } & $\mathrm{Co}(\mathrm{II})$ & $395.1(6 .: 17.5), 418.7(758.4), 442.0(504.6)$ \\
\cline { 2 - 3 } & $\mathrm{Ni}(\mathrm{II})$ & $391.5(276.7), 414.1(400.9), 438.4(316.6)$ \\
\cline { 2 - 3 } & $\mathrm{Cu}(\mathrm{II})$ & $397.4(833.1), 420.2(954.5), 444.4(573.6)$ \\
\cline { 2 - 3 } & $\mathrm{Zn}(\mathrm{II})$ & $395.3(666.9), 416.9(813.1), 440.5(5745)$ \\
\cline { 2 - 3 } & $\mathrm{H}^{+}$ & $394.4(861.2) .418 .9(989.3), 441.8(635.5)$ \\
\hline \multirow{5}{*}{$\mathrm{L}^{2}$} & $\mathrm{Nil}$ & $390.2(86.8) .411 .8(115.2), 436.7(93.41)$ \\
\cline { 2 - 3 } & $\mathrm{Cr}(\mathrm{III})$ & $396.4(846.9), 421.9(988.1), 444.1(611.2)$ \\
\cline { 2 - 3 } & $\mathrm{Mn}(\mathrm{II})$ & $390.4(129.4), 411.4(173.8), 440.1(121.8)$ \\
\cline { 2 - 3 } & $\mathrm{Fe}(\mathrm{II})$ & $390.6(412.2), 413.9(506.6), 439.5(370.5)$ \\
\cline { 2 - 3 } & $\mathrm{Co}(\mathrm{II})$ & $391.5(300.5), 414.1(366.1), 440.7(274.9)$ \\
\cline { 2 - 3 } & $\mathrm{Ni}(\mathrm{II})$ & $388.7(65.7) .408 .6(108.3), 435.8(86.7)$ \\
\cline { 2 - 3 } & $\mathrm{Cu}(\mathrm{II})$ & $396.1(589.8), 416.8(678.8), 442.8(413.6)$ \\
\cline { 2 - 3 } & $\mathrm{Zn}(\mathrm{II})$ & $394.2(463.9), 416.2(551.9), 439.6(398.6)$ \\
\cline { 2 - 3 } & $\mathrm{H}^{+}$ & $394.2(661.2), 418.3(725.3), 441.8(635.5)$ \\
\hline
\end{tabular}


Table- III: Fluorescence output in terms of quantum yield $\left(\Phi_{\mathrm{F}}\right)$ of $\mathbf{L}^{\mathbf{1}}$ and $\mathbf{L}^{\mathbf{2}}$ with different metal ion inputs ${ }^{\mathrm{a}}$

\begin{tabular}{|c|c|c|c|c|}
\hline Fluorophore & $\begin{array}{c}\text { Cationic } \\
\text { input }\end{array}$ & $\begin{array}{c}(\mathrm{O}, \mathrm{O}) \text { Band } \\
\text { position }(\mathrm{nm})\end{array}$ & $\begin{array}{c}\text { Fluorescence } \\
\text { output }\left(\Phi_{\mathrm{F}}\right)\end{array}$ & FEF \\
\hline \multirow{4}{*}{} & $\mathrm{Nil}$ & 390.0 & 0.012 & 1 \\
\cline { 2 - 5 } & $\mathrm{Cr}(\mathrm{III})$ & 398.2 & 0.108 & 9.0 \\
\cline { 2 - 5 } & $\mathrm{Mn}(\mathrm{II})$ & 390.8 & 0.036 & 3.0 \\
\cline { 2 - 5 } & $\mathrm{Fe}(\mathrm{II})$ & 397.4 & 0.019 & 1.6 \\
\cline { 2 - 5 } & $\mathrm{Co}(\mathrm{II})$ & 395.1 & 0.077 & 6.4 \\
\cline { 2 - 5 } & $\mathrm{Ni}(\mathrm{II})$ & 391.5 & 0.016 & 1.3 \\
\cline { 2 - 5 } & $\mathrm{Cu}(\mathrm{II})$ & 397.4 & 0.098 & 8.1 \\
\cline { 2 - 5 } & $\mathrm{Zn}(\mathrm{II})$ & 395.3 & 0.088 & 7.3 \\
\cline { 2 - 5 } & & & & \\
\hline \multirow{5}{*}{$\mathbf{L}^{2}$} & $\mathrm{Nil}$ & 390.2 & 0.013 & 1 \\
\cline { 2 - 5 } & $\mathrm{Cr}(\mathrm{III})$ & 396.4 & 0.126 & 9.7 \\
\cline { 2 - 5 } & $\mathrm{Mn}(\mathrm{II})$ & 390.4 & 0.018 & 1.4 \\
\cline { 2 - 5 } & $\mathrm{Fe}(\mathrm{II})$ & 390.6 & 0.047 & 3.6 \\
\cline { 2 - 5 } & $\mathrm{Co}(\mathrm{II})$ & 391.5 & 0.039 & 3.0 \\
\cline { 2 - 5 } & $\mathrm{Ni}(\mathrm{II})$ & 388.7 & 0.011 & 0.8 \\
\cline { 2 - 5 } & $\mathrm{Cu}(\mathrm{II})$ & 396.1 & 0.077 & 5.9 \\
\cline { 2 - 5 } & $\mathrm{Zn}(\mathrm{II})$ & 394.2 & 0.068 & 5.2 \\
\cline { 2 - 5 } & & & & \\
\hline
\end{tabular}

${ }^{\text {a }}$ Experimental conditions: In dry THF concentration of $\mathrm{L}^{1}$ and L2 $0.000001 \mathrm{M}$ and concentration of metal ionic input was $0.0001 \mathrm{M}$. Excitation were fixed at $368 \mathrm{~nm}$ with band pass $5.0 \mathrm{~nm}$ and emission band pass was $5.0 \mathrm{~nm}$; temperature, $5^{\circ} \mathrm{C}$, $\Phi \mathrm{F}$ calculated by comparison of emission spectrum with that of anthracence $(\Phi F=0.297)$ taking area under the total emission.

The tertiary nitrogen atoms of fluoroionophores would be promoting coordination between $\mathrm{L}^{1}$ and $\mathrm{L}^{2}$ added transition metal ions. The effect of different metal ions along with $\mathrm{H}^{+}$as inputs in the fluorescence emission spectra of $\mathrm{L}^{1}$ and $\mathrm{L}^{2}$ are shown in Figures $4 \& 5$ and Table 4. Further quantum yields of were calculated for both these fluoroionophores in presence of various metal ionic inputs. The quantum yield increased maximum ( 9 to 10 times) in both the cases when $\mathrm{Cr}$ (III) ion is used as input (Fig. 4, Fig. 5 and Table IV) in dry THF medium.

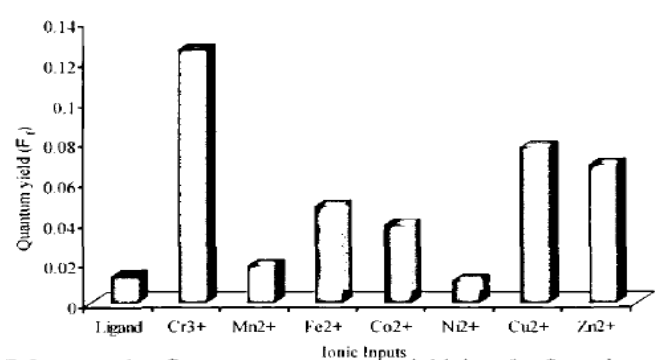

Fig. 4. Bar chart view of comparative fluorescence quantum yield for fluoroionophore $\mathrm{L}^{1}$ along with the metal ion inputs.

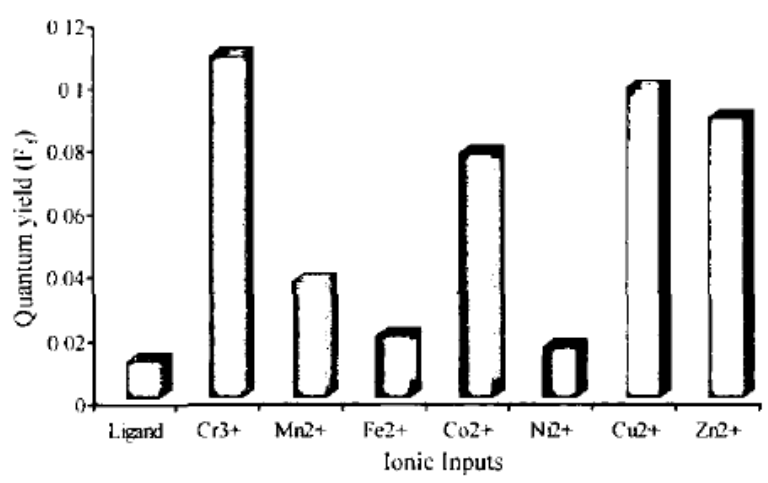

Fig. 5. Bar chart view of comparative fluorescence quantum yield for fluoroionophore $\mathrm{L}^{2}$ along with the metal ion inputs.
In cases of $\mathrm{Cu}(\mathrm{II})$ fluorescence enhancement factor (FEF) are 8 and 6 for $\mathrm{L}^{1}$ and $\mathrm{L}^{2}$ respectively whereas FEF are 7 and 5 with the $\mathrm{Zn}(\mathrm{II})$. The $\mathrm{Co}(\mathrm{II})$ also showed about 6 and 3 times fluorescence enhancement in $\mathrm{L}^{1}$ and $\mathrm{L}^{2}$ respectively in similar experimental conditions. No effect or slight quenching was observed in case of $\mathrm{Ni}(\mathrm{II})$. The poor performance with respect to fluorescence recovery of these systems with transition metal ions compared to the similar cryptand based system reported in the literature [6], [7] could be due to huge steric hindrance of six attached anthryl moieties. Steric hindrance does'nt allow encapsulation of metal ion inside the cryptand's cavity and therefore, efficient recovery of the fluorescence output does not take place.

\section{CONCLUSION}

Solution state studies on this derivative along with another hexa anthryl functionalized cryptand of different cavity show 6-10 times fluorescence intensity enhanced upon the addition of transition metal ions. These systems as well as new cryptand based systems should be attempted in sensing applications in solution as well as in solid surface and molecular self-assembly studies to encapsulate different guests of biological and environmental relevant. If successful, these studies should provide important results both in fundamental and applied research. Solution state fluorescence studies on these fluoroionophores show only 6-10 times enhancement of fluorescence in cases of $\mathrm{Cr}(111), \mathrm{Cu}(11), \mathrm{Zn}(11)$, and $\operatorname{Co}(11)$.

\section{ACKNOWLEDGMENT}

This work is financially supported by DST-SERB, India under Early Career Research Award (ECR/2015/000318).

P. L., V. J., M.K and acknowledges Kalasalingam University (KARE) for PhD fellowship. The authors thank Dr. Shasi Anand, The Vice-President of Kalasalingam University, (KARE) for his constant support.

\section{REFERENCES}

1. Solid State Structural of Chloroform-Benzene-Chloroform Adduct Trapped in Hexaanthryl Octaaminocryptand Channels, P. S. Lakshminarayanan, D. Krishna Kumar, and P. Ghosh, J. Am. Chem. Soc. 2006, 128, 9600-9601.

2. Counter Anion Controlled Water Cluster Recognition in Protonated Octaamino Cryptand, P. S. Lakshminarayanan, D. K. Kumar, and P. Ghosh, Inorganic Chemistry, 2005, 44, 7540-7546.

3. Formation of an Infinite 2D-Layered Water of $\left(\mathrm{H}_{2} \mathrm{O}\right)_{45}$ Cluster in a Cryptand-Water Supramolecular Complex: A Template Effect, P. S. Lakshminarayanan, E. Suresh, and P. Ghosh, J. Am. Chem. Soc. 2005, 127, 13132-13133.

4. Formation of Hybrid Water-Chloride Structure with Discrete Undecameric Water Self-Assembly in a Heptaprotonated Octaamino Cryptand, P. S. Lakshminarayanan, E. Suresh, and P. Ghosh, Angew. Chem.Int. Ed. 2006, 48, 3807-3811.

5. Recognition of Water-Acetonitrile-Water Cluster in a Picrate Salt of Octaaminocryptand, I. Ravikumar, P. S. Lakshminarayanan, E. Suresh and P. Ghosh, Crystal Growth \& Design, 2006, 6, 2630-2633.

6. X-ray crystallographic Investigations of an azacryptand and its bis-protonated salt: Intearction of acyclic water trimer and $\mathrm{CH} \cdots \pi$ interactions in T-shaped Benzene dimer P. S. Lakshminarayanan, D. Krishna Kumar, I. Ravikumar, B. Ganguly and P. Ghosh, Synt. React. Inorg. Metal-Org. Nano Metal Chem. 2008, 38:1, 2-11. (Invited Article in "Special Issue on

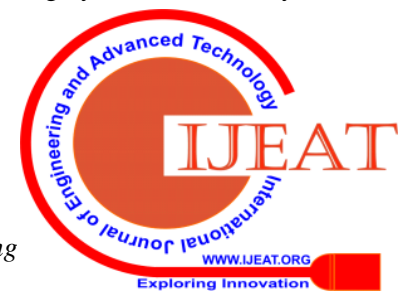


Water Cluster")

7. (a) Amendola, V.; Fabbrizzi, 1..; Foti, F.; LicchcIli, M.; Mangano, c.; Pallavicini, P.; Poggi. A.; Sacchi. D.; Taglietti, A. Cuord. Chem, Rev. 2006, 250,273. (b) Bharadwaj. P. K. Frog. Inorg. Chem. 2003,51,251 (e) Prodi,; Bolletta, F.; Montalti, M.; Zaccheroni, N, Coord. ChclI7. Rev, 2000, 205, 59. (d) Valeur, B.: Leray, I. Coord. Chem. Rev. 2000 205, 3. (e) Ramachandram, B.; Saroja, G.; Sankaran. N. E.; Samanta, A. 1. Phys. Chem. B. 2000, 10-1, 11824. (I) de Silva, A. P.; Gunaratne, H. Q. N.; Gunnlaugsson, T.; Iluxley, A. J. M.; McCoy, C. P.; Rademacher, J. T.; Rice, T. E. Chem. Rev. 1997, 97, 1515. (g) Fluorescent

\section{AUTHORS PROFILE}

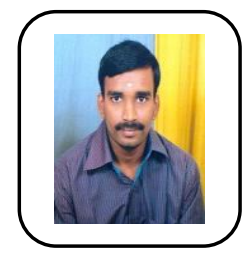

Dr. Lakshminarayanan Piramuthu received his doctoral degree in chemistry from Indian Association for the Cultivation of Science, he is also worked as Research Scientist at Institute of Bioengineering and Nanotechnology, IBN, Singapore. At present he is Professor of Chemistry, Kalasalingam Academy of Research and Education. His work has resulted in the publication of over 30 papers in top quality journals, Piramuthu has an exceptionally Kolkatta, India under the guidance of Professor. Pradyut Ghosh. Dr. Lakshminarayanan strong background in Anion Sensing and Supramolecular chemistry. Also, Dr. Lakshminarayanan worked as a postdoctoral researcher in the Department of Chemistry, Texas A \& M University, Texas, USA, University of Oregon, Oregon USA, National Institute for Material Science, Tsukuba, Japan and before join in Kalasalingam Academy of Research and Education, Krishnankoil, Tamilnadu India such as Angewandte Chemie, the Journal of the American Chemical Society, Inorganic Chemistry, and Chemical Communications.

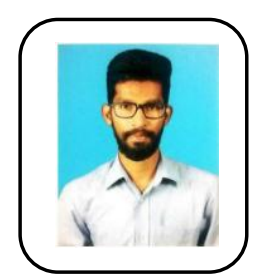

Mr. Kumaresan Murugesan received his B.Sc and M.Sc in chemistry from the NGM College and Karunya University respectively. He is pursuing doctoral degree in Chemistry at Kalasalingam Academy of Research and Eucation(KARE) under the guidance of Dr. Lakshminarayanan Piramuthu. Mr. M. Kumaresan has a research interest on Host-guest chemistry. He has published over 5 research article in reputed international journals.

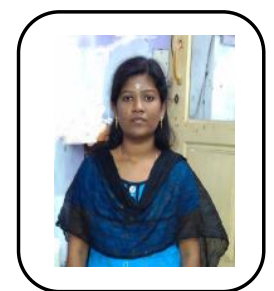

Ms. Vanthana Jeyasingh, her B.Sc and M.Sc in chemistry from Sri Sarada College for women, Tirunelveli, and APC Mahalaxmi College for women, Tuticorin, India respectively. She is pursuing doctoral degree in Chemistry at Kalasalingam Academy of Research and Eucation(KARE) under the guidance of Dr. Lakshminarayanan Piramuthu. Ms. Vanthana Jeyasingh has a research interest on Host-guest chemistry. She has published over 5 research article in reputed internationals.

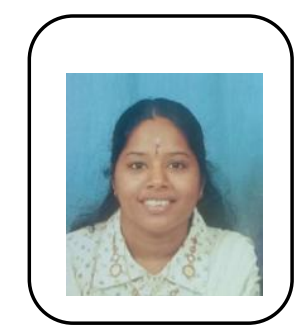

Mrs. Sudha Lakshminarayanan her B.Sc and M.Sc in chemistry from the Sri Paramakalyani College, Alwarkuruchi, India and her M.Phil degree in chemistry from Bharathidasan university, Trichy. Presently She is working as Assistant Professor at JP College of Arts and Science, Agarakattu, Tamilnadu. She is pursuing doctoral degree in Chemistry at Kalasalingam Academy of Research and Eucation (KARE) under the guidance of Dr. Geetha Das and Dr. Selvapalam. She has research interest on Host-guest chemistry. She has published over 5 research article in reputed international journals.

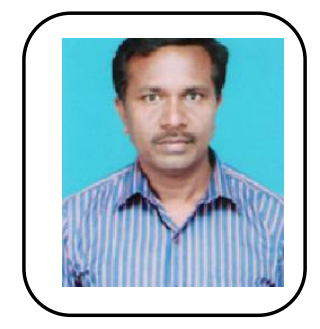

Dr. Narayanan Selvapalam received his M.S and $\mathrm{PhD}$ degrees from Mysore University and IIT Delhi respectively. He is presently working as Associate professor at Kalasalingam Academy of Research and Education (Kalasalingam University). His research interests include supramolecular chemistry, chemistry of cucurbiturils and cyclodextrines, organic synthesis and sensors. 